\title{
Sándor Ferenczi (1873-1933): o início de um pensamento
}

\author{
Gabriel Zaia Lescovar \\ Gilberto Safra \\ Universidade de São Paulo
}

\begin{abstract}
Resumo
O presente trabalho apresenta uma leitura hermenêutica do primeiro artigo psicanalítico do, até então, médico húngaro Sándor Ferenczi. Por meio do texto “Do alcance da ejaculação precoce”, de 1908, buscamos explicitar o percurso inicial do pensamento teórico-clínico psicanalítico ferencziano. Enfatizamos o conceito de neurose de angústia de Freud, como a principal matriz clínica emprestada pelo autor para desenvolvimento de suas próprias contribuições. A partir da discussão dos fatores fisiológicos envolvidos no conceito freudiano procuramos explicitar os questionamentos ferenczianos envolvidos segundo o campo sócio-cultural das relações entre homem-mulher, visando destacar a ampliação do conceito, tal como Ferenczi o concebe. Dessa forma, ilustramos o surgimento de uma tradição em psicanálise em que o processo de subjetivação humana passou, necessariamente, a ser atrelado aos aspectos sócio-culturais, às relações interpessoais e à dimensão ética humana.
\end{abstract}

Palavras-chave: freud; ferenczi; história da psicanálise; neurose de angústia

\begin{abstract}
Sándor Ferenczi (1873-1933): the beginning of a thought. The present work presents a hermeneutic reading of the first psychoanalytic article of the Hungarian doctor Sándor Ferenczi. Using the text "The scope of precoce ejaculation”, written in 1908, we try to expose the beginning of Ferenczi's psychoanalytical thought. We take Freud's concept of anxiety neuroses as the main clinical matrix borrowed by the author for the development of his own contributions. From the discussion on physiological factors present on Freud's concept we explicate Ferenczi's expansion of the concept to the cultural field, when he discusses the relationship between man and woman. From this point of view, we focus on the beginning of a new tradition in psychoanalysis, which comprehends the human subjectivation process through the perspectives of the cultural aspects, the interpersonal relations and the human ethics.
\end{abstract}

Keywords: freud; ferenczi; history of psychoanalysis; anxiety neuroses

Confusão de línguas - a importância dos estudos históricos em psicanálise

$\mathrm{D}$ iferentemente da filosofia e da religião, a Psicanálise se funda na própria e constante reformulação através dos desafios clínicos encontrados ao longo de sua história (Freud 1923/1976). Original e perpetuamente vinculada ao sofrimento de seus pacientes, sua difusão atingiu níveis extremamente complexos de diversidade e heterogeneidade em suas diferentes escolas. Marcada pelas experiências clínicas de cada autor, paradoxalmente, o mesmo fator que deveria levar ao enriquecimento, passou a tomar proporções dogmáticas, conduzindo às já conhecidas dissidências no movimento psicanalítico. Em resposta ao compromisso ético investigativo-terapêutico que a fundou, os estudos históricos em Psicanálise tornam-se presentes e são mar- cados, em linhas gerais, pela polivalência dos aspectos históricos e culturais, que deixaram marcas sobre as concepções, os recursos terapêuticos e as técnicas analíticas (Gay, 1989; Mezan, 1985; Roudinesco, 1988; 1989; 1995). O estudo histórico poderá trazer, para o primeiro plano de investigação, as implicações das diversidades geográficas, históricas, biográficas, políticas e institucionais, as quais norteiam as práticas psicanalíticas, seus ensinamentos e pesquisa.

Mezan (1988), em "Problemas de uma história da Psicanálise”, aborda alguns pressupostos metodológicos necessários para a realização desse empreendimento. Ele apresenta uma das principais problemáticas no exercício do ensino, difusão e pesquisa da disciplina: a ausência de um quadro conceitual coerente entre as diversas escolas em Psicanálise. Partindo, assim, da constatação de que "sob o mesmo voca- 
bulário se ocultam concepções bastante diferentes", ou, mesmo, que "o lugar e a importância teórica" dos conceitos não são idênticos, o autor propõe a realização de estudos históricos da psicanálise - visando desfazer incompreensões ou leituras equivocadas. Mezan (1988) implicitamente defende os estudos hermenêuticos capazes de salientar as discrepâncias e/ou divergências entre os diferentes autores psicanalíticos como o caminho necessário que permitirá a renovação e perpetuação do instrumental teórico-investigativo inicialmente criado por Freud. Para os propósitos deste artigo, serão empregados os instrumentais propostos por Gadamer (1976) e Figueiredo (1999).

O clima psicanalítico, as questões julgadas pertinentes, o modo de construir teorias a partir de um conjunto de evidências partilhadas e por isto mesmo raramente interrogadas, são governados por referenciais teóricos amplamente divergentes. E, no entanto, a origem de todos estes referenciais é a obra de Freud. Eis-nos de novo diante do problema da história da psicanálise: como e por que se construíram estes referenciais teóricos? De onde vêm suas armações conceituais? Por que tiveram sucesso, maior ou menor, em diferentes épocas e lugares? (...) Trata-se de fazer o levantamento das "próprias concepções” - quantas existem, no que consistem suas diferenças, etc. - e simultaneamente pesquisar quais poderiam ter sido os "fatores culturais" que, incidindo sobre a teoria herdada de Freud, acabaram por infleti-la nas direções que conhecemos. Em suma: levar a sério a idéia de uma história da psicanálise, não enquanto uma seqüência de percalços externos e contingentes em seu trajeto, referentes apenas ao "movimento" psicanalítico (cisões, divergências, emigrações por motivos políticos, etc.), mas enquanto algo intrínseco ao desenvolvimento teórico da disciplina fundada por Freud. (Mezan 1988, p. 19)

Em linhas gerais, torna-se necessário depreender a matriz clínica a qual cada autor do campo psicanalítico se vincula para erigir sua própria teoria e, mais que isso, compreender seus desdobramentos teórico-clínicos posteriores. Para Mezan (1988), o conceito de matriz clínica apresenta uma definição bastante precisa, trata-se de "um tipo determinado de organização psicopatológica, com sua estrutura própria, seus conflitos originadores e suas modalidades próprias de defesa” (Mezan, 1988, p. 27).

Mezan (1988), desta forma, defende alguns pressupostos metodológicos e epistemológicos de base, que podem ser definidos através do grau de congruência entre quatro dimensões essenciais de qualquer teoria psicanalítica: a teoria geral sobre o psiquismo humano, a teoria sobre sua gênese e desenvolvimento, a teoria sobre normalidade e patologia psíquicas e, finalmente, as concepções sobre processo psicoterápico e conduções técnicas. Como ponto de partida da investigação epistemológica sugere-se a averiguação dos mitos de criação e origem histórica de cada escola diversa de psicanálise. Segundo Mezan (1988), todo mito de origem das correntes em psicanálise coincide com as definições mesmas das finalidades terapêuticas, que, por sua vez, necessariamente, aglutinam os quatro níveis citados acima. Tais mitos de origem podem ser didaticamente apresentados em quatro grades categoriais (pp. 34-35):

A. Modelos redutores da história da psicanálise [ou, ausência do fator historicizante]:

(a) redução [única e exclusivamente] da psicanálise ao pensamento de Freud;

(b) redução das descobertas psicanalíticas a fatos que podem ser incorporados a outras disciplinas, sem que se conserve seu modo de descoberta [negação das maneiras particulares pelas quais a psicanálise chegou às suas conclusões e finalidades terapêuticas];

B. Modelos lineares da história da psicanálise:

(a) por aglutinação externa: o modelo cronológico-geográfico [negação das influências histórico-sócio-culturais locais sobre a disciplina];

(b) por contigüidade vertical: o modelo kleiniano do aprofundamento [negação das diferenças clínicas e teóricas];

(c) por continuidade horizontal: o modelo ego-psicologista da ampliação [negação das diversidades clínicas, teóricas e ontológicas];

C. Modelos interpretativos da história da psicanálise [redução das diferenças de pensamentos aos instrumentais psicanalíticos, como próprios e suficientes]:

(a) utilizando como categoria central a resistência: o modelo lacaniano;

(b) utilizando como categoria central a repetição e a transferência: o modelo de F. Roustang;

(c) utilizando como categoria central o après-coup e os mecanismos do processo primária: o modelo de J. Laplanche;

D. Modelos sobredeterminantes da história da psicanálise: os que reconhecem a existência de várias coordenadas, sem cuja interação a história da psicanálise é absolutamente incompreensível. (...) [entre as coordenadas se encontram: as mútuas influências dos conceitos e de suas variações em um mesmo autor - e nas diferentes escolas; a diversidade de bases e experiências clínicas - as matrizes clínicas; e, as complexidades teórico-técnicas].

Além dos aspectos históricos, geográficos, sócio-culturais, políticos e institucionais, tal como destacados por Mezan (1988), poder-se-ia acrescentar a obrigatoriedade da inclusão e consideração dos aspectos biográficos que motivaram cada autor a realizar um determinado percurso em psicanálise. Tais elementos biográficos serão empregados para iluminar discrepâncias, contradições e esforços pessoais de Ferenczi à difusão da Psicanálise através da Medicina.

Qual seria, então, a matriz clínica de que Ferenczi se utiliza para escrever esse seu primeiro artigo de 1908? Qual a leitura privilegiada que Ferenczi realiza acerca do fundador da psicanálise? Por que, enfim, estudar Ferenczi? 


\section{A importância da clínica ferencziana para a terapêutica da atualidade}

Sándor Ferenczi (1873-1933) fez parte da primeira geração de psicanalistas. Reconhecidamente "o pioneiro dos pioneiros” (Alexander, Eisenstein, \& Grotjahn, 1981), Ferenczi inaugurou possibilidades de compreensão e condução de casos clínicos considerados difíceis, ou incapazes de desenvolver neurose de transferência e que, até hoje, estão presentes com freqüência em consultórios e ambulatórios. Esses pacientes encontram-se incapazes de sonhar, fantasiar, ter perspectivas de futuro... enfim, apresentam problemáticas psíquicas predominantemente narcísicas, ou marcadas por distúrbios psicossomáticos e aspectos psicóticos (Bokanowski, 1990; Pinheiro, 1993; Sanches, 1993). Por meio de suas inovações técnicas, Ferenczi contribuiu para uma ampliação dos recursos terapêuticos e diagnósticos, assim como, para uma reflexão mais aprofundada do exercício ético da psicanálise e adequação da técnica de acordo com as necessidades psíquicas do paciente em questão. (Borgogno, 2001; Cahn, 1983; Haynal, 1995; Migone, 1994; Sanches, 1993; 1994).

\section{Contribuições do pensamento ferencziano para a compreensão da história dos conceitos e da clínica psicanalíticos}

O aprofundamento da obra ferencziana poderá trazer esclarecimento e subsídios para uma melhor compreensão/distinção de outros autores fundamentais e posteriores do movimento psicanalítico, e que também tiveram que se deparar com as problemáticas clínicas anteriormente destacadas por Ferenczi, tais como: Anna Freud, Melanie Klein, Alice e Michael Balint, Nicolas Abraham, Maria Torok, Kohut, Bion, Winnicott entre outros (Aguayo, 1997; Bethelard \& YoungBruehl, 1999; Cintra, 1992; 1993; Deri, 1990; Gerber, 1999; Harmat, 1987; Haynal, 1995; Hazan, 1999; Katz, 1996; Landa, 1999; Martin-Cabre, 2001; Nachin, 2001; Sanches, 1994).

Ausência de leituras sistemáticas e desconstrutivas da obra, fundamentação e discrepâncias internas da evolução clínica psicanalítica de Ferenczi

Torna-se de fundamental importância a promoção de estudos críticos dos grandes autores da Psicanálise, como forma de permitir a configuração das similaridades e diferenças teórico-clínicas entre eles, assim como no interior do desenvolvimento teórico-clínico de um mesmo autor. Tal como defende Figueiredo (1999), trata-se de favorecer as explanações das identidades e dos elementos heterogêneos silenciosos que permeiam a obra do autor - e, freqüentemente, encontram-se pouco esclarecidos - visando à sua maior compreensão e à configuração do exercício crítico da psicanálise.

Embora os textos pré-psicanalíticos de Ferenczi representem a história da construção do seu pensamento, o texto publicado em 1908 é considerado como marco de sua produção psicanalítica (Casonato 1993; Ferenczi 1994; Lorin 1983). Assim, o resgate histórico ilustrativo e compreensivo da matriz clínica desse artigo oportuniza demarcar o primeiro im- pacto da obra e da pessoa de Freud sobre o pensamento e clínica ferenczianos.

$O$ alcance do primeiro texto psicanalítico ferencziano - a neurose de angústia como matriz clínica

"Do alcance da ejaculação precoce" (Ferenczi, 1908a/ 1991) é um texto marcado pelo início das discussões, trocas de correspondências e opiniões entre Freud e Ferenczi. Naquele momento, Ferenczi se familiarizava com os conceitos e com a pesquisa psicanalíticos. Formado em Medicina - esta foi a sua porta de entrada (e de leitura) da obra freudiana curiosamente, Ferenczi havia sido solicitado por seu amigo e editor Max Schächter a realizar uma resenha da obra "Interpretação dos sonhos”, de Freud (1900/1976). Após uma rápida leitura, Ferenczi considerou-o irrelevante (Sabourin, 1988). Tal como ele próprio torna público posteriormente (Ferenczi 1908b/1991), o seu forte ensejo em demonstrar a importância dos achados psicanalíticos ao público médico se deu através do reconhecimento pessoal da veracidade das constatações freudianas (Ferenczi, 1908b/1991). Este propósito se revela por meio da escolha do periódico para publicação de seu artigo: o Journal Medical de Budapest. Tal artigo teve não somente o objetivo de discutir assuntos psicanalíticos entre os psicanalistas da época, mas também de difundir algumas idéias de Freud ante o público médico.

Ferenczi deixa transparecer o seu objetivo na primeira nota de rodapé daquele texto; mas, também em correspondência a Freud, de 18 de janeiro de 1908 (Falzeder, Brabant, \& Giampieri, 1994), ele assim escreve:

\section{Ilustríssimo Senhor Professor,}

Sou-lhe imensamente grato por sua disposição em receber-me, a mim, um desconhecido para o senhor, na companhia do colega Dr. Stein. Agradeço-lhe, Professor, não apenas pelo fato de estar desejoso de um contato pessoal com o senhor, de cujas teorias tenho me ocupado há aproximadamente um ano, mas também por esperar deste encontro muitos ensinamentos úteis e instrutivos.

Agora mais do que nunca necessito adquirir mais conhecimento sobre o tema, pois estou prestes a ter que falar sobre o conjunto de suas descobertas para um público médico que é, em parte, ignorante e, em parte, mal-informado sobre o assunto. Para tanto, tenho presente o seu axioma, segundo o qual é preciso levar em conta os ouvintes para se poder efetivamente dizer a verdade. Portanto, trarei inicialmente apenas fatos bastante óbvios, facilmente compreensíveis, por este motivo, convincentes. De qualquer forma, trata-se de uma tarefa muito difícil. Precipitando-me sem tato, eu estaria só prejudicando a causa: gostaria de ser um mestre, pelo menos, na delimitação do assunto.

Desculpe-me por entrar imediatamente in media res. O tema deixa qualquer um facilmente entusiasmado.

Agradecendo novamente por sua amabilidade, finalizo, aguardando com prazer o encontro do dia 02 de fevereiro,

Cordialmente,

Dr. Ferenczi. (p. 62) 
Depois dessa visita, Ferenczi (1908b/1991) falou sobre “As neuroses à luz do ensino de Freud e da psicanálise” na Sociedade Real de Médicos de Budapeste e, ainda envolvendo público médico, participou de uma série de conferências intitulada "Sobre as psiconeuroses” (Ferenczi, 1909/1991).

Conforme já anunciado na correspondência, o objetivo do autor era difundir a psicanálise no meio médico. Após rejeitar as afirmações psicanalíticas freudianas e assumir as suas resistências em lidar com as questões que a psicanálise trazia, Ferenczi vislumbra o bom instrumento de trabalho que a psicanálise apresentava. Em um ato restitutivo, ele se incumbe da "missão" de difundir a psicanálise no meio médico, isto é, de ser o interlocutor da obra freudiana para os médicos (seus iguais).

Já no primeiro parágrafo do texto, Ferenczi pinça, de toda a obra de Freud disponível na época, o conceito de neurose de angústia (o autor até destaca o conceito no texto). De acordo com a obra freudiana, Laplance e Pontalis (1992) consideram por neurose de angústia:

Tipo de doença que Freud isolou e diferenciou:

(a) do ponto de vista sintomático, da neurastenia, pela predominância da angústia (espera ansiosa crônica, acessos de angústia ou equivalentes somáticos desta);

(b) do ponto de vista etiológico, da histeria. A neurose de angústia é uma neurose atual, mais especificamente caracterizada pela acumulação de uma excitação sexual que se transformaria diretamente em sintoma, sem mediação psíquica. (p. 302)

Enquanto as neuroses atuais (neurastenias e neuroses de angústia) são definidas segundo a insatisfação sexual, as psiconeuroses definem-se segundo os conflitos psíquicos internos. Para maior clareza, Laplance e Pontalis (1992) esclarecem:

(a) a origem das neuroses atuais não deve ser procurada nos conflitos infantis, mas no presente;

(b) nelas, os sintomas não são uma expressão simbólica e superdeterminada, mas resultam diretamente da ausência ou da inadequação da satisfação sexual.

Freud inclui inicialmente nas neuroses atuais a neurose de angústia e a neurastenia, e propôs posteriormente incluir também a hipocondria.

A expressão neurose atual aparece em 1898 na obra de Freud para designar a neurose de angústia e a neurastenia, mas a noção de uma especificidade dessas afecções relativamente às outras neuroses definiu-se ainda antes de suas investigações sobre a etiologia das neuroses, quer na correspondência com Fliess, quer nas publicações dos anos de 1894-96.

A oposição das neuroses atuais às psiconeuroses é essencialmente etiológica e patogênica. Nos dois tipos de neurose a causa é realmente sexual, mas aqui ela deve ser procurada em “desordens da vida sexual atual” e não em "acontecimentos importantes da vida passada”. O termo "atual” deve, pois, ser tomado em primeiro lugar no sentido de uma "atualidade" no tempo. Por outro lado, essa etiologia é somática e não psíquica: "A fonte de excitação, o fator desencadeante da perturba- ção, está no domínio somático, enquanto na histeria e na neurose obsessiva está no domínio psíquico”. Na neurose de angústia este fator seria a ausência de descarga da excitação sexual, e na neurastenia um apaziguamento inadequado dela (masturbação, por exemplo).

Por fim, o mecanismo de formação dos sintomas seria somático (por exemplo, transformação direta da excitação em angústia), e não simbólico. O termo atual vem exprimir aqui a ausência daquela mediação que encontramos na formação dos sintomas das psiconeuroses (deslocamento, condensação, etc). Do ponto de vista terapêutico, essas opiniões levam à idéia de que as neuroses atuais nada têm a ver com a psicanálise, pois aqui os sintomas não procedem de uma significação que poderia ser elucidada. (pp. 299/300)

Apesar dessa concepção de Laplance e Pontalis, defendemos aqui a proposição de que Ferenczi, desde o seu primeiro escrito psicanalítico, considera como campo de reflexão e intervenção psicanalíticas (psicoprofilática e/ou secundárias) os próprios adoecimentos concretos e físicos provocados pela organização patológica social.

É fundamental compreender porque Ferenczi escolheu, dentre os conceitos freudianos, o de neurose de angústia para apresentar a psicanálise aos médicos. A neurose de angústia, segundo Freud, é aquela que tem uma concepção fortemente enraizada no fator biológico humano e ocorre devido a uma ausência de satisfação sexual. Freud, ao explicar sua etiologia, utilizava um modelo explicativo mais próximo das concepções e pensamentos dos médicos.

Uma vez que esse conceito era próximo e familiar aos médicos, convinha aos propósitos comuns de Freud e Ferenczi, por constituir-se em importante meio político facilitador da difusão da Psicanálise. No entanto, a freqüência desse conceito nos artigos iniciais de Ferenczi revela, como pano de fundo, o elemento norteador de suas reflexões nessa fase inicial. Em outras palavras, indica que, nesse período, a matriz clínica de Ferenczi é a neurose de angústia. As neuroses atuais seriam a porta de entrada de seu segundo artigo, "As neuroses à luz do ensino de Freud e da Psicanálise” (Ferenczi, 1908b/1991), que, conforme o primeiro texto, também foi endereçado aos médicos da Sociedade Real de Medicina.

Não obstante, o uso que Ferenczi faz da neurose de angústia é próprio. Ele a tomou para indicar a participação da dimensão do real no sofrimento humano. Será a matriz clínica sobre a qual iniciaria a construção de seu próprio pensamento e de seus conceitos psicanalíticos subseqüentes.

No parágrafo inicial do texto analisado aqui, Ferenczi também pôs em discussão um aspecto pouco destacado por Freud (até aquele momento, em sua obra): as implicações da neurose de angústia na mulher. Até então, Freud se utilizava principalmente da problemática masculina para discutir tais agravos. Ferenczi (1908a/1991) escreve:

Além disso, deixando de lado os casos francamente patológicos de ejaculação precoce (quase sempre associada a inúmeros outros sinais de neurastenia sexual e sempre imputável a uma excessiva masturbação), parece que, de modo geral, o sexo 
masculino apresenta, em relação ao sexo feminino, uma ejaculação precoce relativa. Em outras palavras, mesmo no caso mais favorável, quando a duração da fricção no homem é normal, grande número de mulheres não chega ao orgasmo; seja porque a anestesia permanece completa até o fim, seja porque, tendo-se produzido uma certa excitação libidinal, esta não atinge o grau necessário ao orgasmo, o ato fica concluído para o homem e a mulher fica excitada, mas insatisfeita. (p. 1)

O interesse fundamental de Ferenczi, já neste artigo é a mulher, além da preocupação entre a relação entre as pessoas como ponto de partida para as suas reflexões psicanalíticas (no caso, de diferentes sexos). Freud estava mais voltado para a construção de hipóteses sobre os dinamismos internos de cada indivíduo.

No parágrafo seguinte, Ferenczi (1908a/1991), nova e explicitamente, destacou o seu público alvo: os homens e os médicos.

Esse estado, quando se torna permanente, leva necessariamente a um estado de tensão nervosa; só o egoísmo masculino, sobrevivência do velho regime patriarcal, pôde desviar a atenção dos homens... logo, dos médicos, deste problema. (p. 01)

Ferenczi fez uma crítica à realidade sócio-cultural da época. Além de destacar as condições concretas e reais da cultura como adoecedoras da condição feminina, Ferenczi acrescentou um novo conceito ao texto psicanalítico: o egoísmo.

Através da matriz clínica eleita, Ferenczi, não somente destacou a dimensão do real nas relações humanas, mas também problematizou os aspectos sociais da cultura da época vinculados ao regime patriarcal. Ele iniciou a introdução de uma visão bastante particular de sua forma de compreender o sofrimento humano e a clínica psicanalítica decorrente, na qual realizou uma leitura do ambiente humano relacional e também sócio-cultural.

No próximo parágrafo, o autor em questão, além de perpetuar seu objetivo inicial de difundir a psicanálise no meio médico, apresentou um segundo objetivo interventivo.

Estamos habituados desde longa data a admitir que somente os homens têm direito à libido sexual e ao orgasmo; estabelecemos e impusemos às mulheres um ideal feminino que exclui a possibilidade de exprimir e de reconhecer abertamente desejos sexuais, e só tolera a aceitação passiva, ideal que classifica as tendências libidinais, por muito pouco que elas se manifestem na mulher, nas categorias patológico e "vicioso". (Ferenczi, 1908a/1991, pp. 1-2)

Ferenczi estava buscando realizar uma intervenção, tanto junto aos médicos quanto ao público mais geral, a respeito das problematizações que as questões sócio-culturais da época representavam à condição da mulher, à sexualidade e ao papel imposto a cada um dos sexos. Nos parágrafos seguintes, continuou a realizar uma argumentação em defesa da liberdade sexual das mulheres.

Se os homens rompessem seu modo de pensar egocêntrico para imaginar uma vida em que lhes tocasse sofrer constantemente a interrupção do ato antes da resolução orgástica da tensão, dar-se-iam conta do martírio sexual suportado pelas mulheres e do desespero provocado pelo dilema que as reduz a escolher entre o respeito a si mesmas e a plena satisfação sexual. Eles compreenderiam melhor por que uma porcentagem tão importante de mulheres foge ao dilema através da doença. (Ferenczi, 1908a/1991, p. 2)

Conforme buscamos demonstrar, Ferenczi tinha uma possibilidade de falar das mulheres, de se identificar com os aspectos femininos da experiência humana que Freud não tinha. Freud freqüentemente expressava sua dificuldade para se colocar no lugar da mulher e, assim, compreender seus dilemas e especificidades (Freud, 1931/1976).

Já nesse artigo inicial, Ferenczi começou a introduzir, muito claramente, a questão ética que irá atravessar toda a sua obra psicanalítica. No trecho destacado acima, introduziu uma nova perspectiva ao campo psicanalítico: a noção de dignidade pessoal e seu sofrimento correspondente. Tal aspecto será, mais tarde, claramente expresso em um de seus artigos finais, “Confusão de línguas entre os adultos e a criança: a linguagem da ternura e da paixão” (Ferenczi, 1933/ 1992). As questões éticas começavam a surgir como elementos que participariam do adoecimento humano (neste caso, da neurose de angústia), assim como a consideração dos aspectos culturais envolvidos na compreensão das dificuldades entre os sexos, ampliando o alcance da discussão psicanalítica:

A teleologia própria do raciocínio humano não se resigna facilmente ao postulado de que "no melhor dos mundos possíveis” um funcionamento orgânico tão elementar deve apresentar naturalmente igual diferença de duração para resultar na satisfação em ambos os sexos. E a experiência parece confirmar, com efeito, que não se trata de uma diferença orgânica nos dois sexos, mas de uma diferença de condições de vida e de pressão cultural, para explicar essa “discronia” na sexualidade dos cônjuges. (Ferenczi, 1908a/1991, p. 2)

Ferenczi teceu ainda uma série de comentários críticos à educação da época:

A maior parte dos homens casa-se após um número maior ou menor (geralmente bastante grande) de aventuras sexuais e a experiência mostra que, nesse domínio, o hábito não acarreta uma elevação do limiar de excitação mas, pelo contrário, propicia uma aceleração da ejaculação. Esse efeito aumenta consideravelmente se - como é indiscutivelmente o caso em $90 \%$ dos homens - a satisfação foi por largo tempo, obtida por via auto-erótica. Por isso, na grande maioria dos homens que se casam, a ejaculação é relativamente precoce.

Em contrapartida, a mulher, durante sua adolescência, é metodicamente subtraída a toda e qualquer influência sexual, quer se trate do plano real ou do plano mental; e, além disso, os esforços tendem a fazê-la detestar e desprezar tudo o que envolva o domínio da sexualidade. Assim, pois, comparada com seu futuro esposo, a mulher que se casa é, do ponto de vista sexual, pelo menos hiperstésica, quando não anestésica. (Ferenczi, 1908a/1991, pp. 2-3) 
Apesar de explicitamente considerar-se desqualificado para a realização de desenvolvimentos sociológicos, desde o seu primeiro parágrafo, Ferenczi assim o faz:

Não me sinto qualificado para extrair as conclusões sociológicas do problema e decidir quem dos dois tem razão: aquele que inclui os homens, por sua vez, na exigência de castidade até o casamento, ou aquele que propõe a emancipação das mulheres. O médico, que apenas busca remédio para os sofrimentos humanos e está menos preocupado com os males da sociedade, inclina-se evidentemente para essa segunda alternativa; ele se sente mais seduzido por uma tendência capaz de provocar uma diminuição da histeria feminina do que por aquela que, ao preconizar a observância da castidade no homem, tende a estender a histeria igualmente ao sexo masculino. (Ferenczi, 1908a/1991, p. 3)

Apesar de suas ressalvas, Ferenczi iniciava uma tradição em psicanálise em que a compreensão da subjetivação humana tornou-se atrelada, necessariamente, aos aspectos sócioculturais, às relações inter-humanas e à dimensão ética.

Em nota de rodapé ao trecho destacado acima, Ferenczi apresentou outro aspecto inovador. Para ele, mais fundamental que o direito de voto feminino, encontrava-se o direito à liberdade sexual. Tal aspecto seria posterior e socialmente retomado pelos movimentos feministas mundiais.

Em minha opinião, as mulheres estão erradas quando crêem que o remédio para seus males seria o direito de voto. Não é o direito à escolha política, mas à escolha sexual que elas deveriam reivindicar com mais sólidas razões. (Ferenczi, 1908a/1991, p. 3)

No entanto, apesar de Ferenczi, já em seu primeiro artigo psicanalítico, se apresentar tão inovador, em um pequeno trecho que se segue, ele demonstrou certa contradição em seus argumentos - própria de um homem fundado em sua época de formação moralista-vitoriana.

Na realidade, não creio que a escolha se reduza a esses dois extremos. Deve existir uma solução para administrar melhor o interesse sexual da mulher, sem que por isso se sacrifique a ordem social fundamentada na família. (Ferenczi, 1908a/1991, p. 03)

Apesar do deslize moralista, entretanto, Ferenczi retomou em suas conclusões a importância dos fatores éticos humanos:

O movimento de iniciação sexual das mulheres antes do casamento constitui um tímido começo nesse sentido. E se o número de sugestões e projetos simplistas e absurdos é enorme, existe, contudo, a esperança de que o procedimento brutal e geralmente praticado que consiste em entregar, no dia do casamento, uma mulher amedrontada e ignorante da sexualidade a um homem já detentor de numerosas experiências, será um dia abandonado. Enquanto vigorarem as condições atuais, não é surpreendente que a ejaculação relativamente rápida do homem e a relativa anestesia da mulher sejam naturalmente admitidas na vida conjugal, e que, em conseqüência da "significação exemplar da sexualidade”, as uniões baseadas na satisfação mútua, ou seja, as uniões felizes sejam tão raras. (Ferenczi, 1908a/1991, p. 3)

\section{Considerações finais}

Este trabalho buscou explicitar o percurso inicial do pensamento e da clínica ferenczianos, detendo-se sobre o conceito de neurose de angústia, como a principal matriz clínica utilizada para as apresentações de seus questionamentos psicanalíticos. Demonstrou-se a inauguração de uma tradição em psicanálise envolvendo a compreensão da subjetividade humana atrelada aos aspectos sócio-culturais, às relações inter-humanas e à dimensão ética.

A partir das descrições freudianas sobre o conceito de neurose de angústia, Ferenczi salientou a dimensão do sofrimento feminino imposto através do regime patriarcal e sugeriu reflexões que marcaram fortemente os movimentos feministas posteriores. Revolucionariamente, Ferenczi apresentou uma ampliação do conceito freudiano, no sentido da participação da vida sócio-cultural, da dimensão concreta real das relações humanas, e, finalmente, por meio da introdução de novas perspectivas ao campo psicanalítico, tais como: dignidade pessoal, egoísmo e regime patriarcal. Ele demarcou a necessidade de inclusão dos aspectos éticos para a devida compreensão dos sofrimentos humanos, inclusive em sua terapêutica. Ferenczi iniciou a possibilidade de reflexão psicanalítica sobre os regimes educacionais envolvidos na instalação e perpetuação de adoecimentos psíquicos. Tais aspectos marcaram toda a obra ferencziana.

\section{Agradecimento}

Os autores agradecem à FAPESP (Fundação de Amparo à Pesquisa do Estado de São Paulo) pelo financiamento da pesquisa de doutoramento “A história da clínica na obra de Sándor Ferenczi”, em processo de realização junto ao Departamento de Psicologia Clínica do Instituto de Psicologia da Universidade de São Paulo.

\section{Referências}

Aguayo, J. (1997). Historising the origins of kleinian psychoanalysis: Klein’s analytic and patronal relationships with Ferenczi, Abraham and Jones (19141927). International Journal of Psychoanalysis, 78(06), 1165-1182.

Alexander, F., Eisenstein, S., \& Grotjahn, M. (1981). A história da psicanálise através de seus pioneiros. Rio de Janeiro: Imago.

Bethelard, F., \& Young-Bruehl, E. (1999). The wise baby as the voice of the true self. Psychoanalytic Quartely, 68(4), 585-610.

Bokanowski, T. (1990). Ferenczi, la technique psychanalytique et les patients difficiles. Revue Française de Psychanalyse, 54(2), 521-531.

Borgogno, F. (2001). Elaticity of technique: the psychoanalytic project and the trajectory of Ferenczi's life. American Journal of Psychoanalysis, 61(4), 391-407.

Cahn, R. (1983). Le proces du cadre ou la pasión de Ferenczi. Revue Française de Psychanalyse, 47(5), 1107-1136.

Casonato, M. (1993). Ferenczi’s preanalytic writing (1899-1908): a listing. Contemporary Psychoanalysis, 29(4), 736-745. 
Cintra, E. M. U. (1992). Melanie Klein: raízes de um pensamento. Dissertação de mestrado não-publicada, Pontifícia Universidade Católica de São Paulo, São Paulo.

Cintra, E. M. U. (1993). Thalassa: matriz de hipóteses kleinianas. Percurso, 6(10), 56-63.

Deri, S. (1990). Great representatives of Hungarian psychiatry: Balint, Ferenczi, Hermann and Szondi. Psychoanalytic Review, 77(4), 491-501.

Falzeder, E., Brabant, E., \& Giampieri, P. (Orgs.). (1994). Sigmund Freud \& Sándor Ferenczi: correspondência (1908-1911) (C. Cavalcanti \& S. K. Lages, Trads.). Rio de Janeiro: Imago.

Ferenczi, S. (1991). Do alcance da ejaculação precoce. In Psicanálise I (Vol. 1, pp. 1-4, A. Cabral, Trad.). São Paulo: Martins Fontes. (Trabalho originalmente publicado em 1908a)

Ferenczi, S. (1991). As neuroses à luz do ensino de Freud e da psicanálise. In Psicanálise I (Vol. 1, pp. 05-22, A. Cabral, Trad.). São Paulo: Martins Fontes. (Trabalho originalmente publicado em 1908b)

Ferenczi, S. (1991). Sobre as psiconeuroses. In Psicanálise I (Vol. 1, pp. 41-56, A. Cabral, Trad.). São Paulo: Martins Fontes. (Trabalho originalmente publicado em 1908c).

Ferenczi, S. (1992). Confusão de línguas entre os adultos e a criança: a linguagem da ternura e da paixão. In Psicanálise IV (Vol. 4, pp. 97-108, A. Cabral, Trad.). São Paulo: Martins Fontes. (Trabalho originalmente publicado em 1933)

Ferenczi, S. (1994). Les écrits de Budapest. Paris: EPEL.

Figueiredo, L. C. (1999). Palavras cruzadas entre Freud e Ferenczi. São Paulo: Escuta.

Freud, S. (1976). Dois verbetes de enciclopédia. In Edição standard brasileira das obras psicológicas completas de Sigmund Freud (Vol. 18, pp. 287-308, C. M. Oiticica, Trad.). Rio de Janeiro: Imago. (Trabalho originalmente publicado em 1923).

Freud, S. (1976). A interpretação dos sonhos. In Edição standard brasileira das obras psicológicas completas de Sigmund Freud (Vol. 04, pp. XVII-648, C. M. Oiticica, Trad.). Rio de Janeiro: Imago. (Trabalho originalmente publicado em 1900)

Freud, S. (1976). A sexualidade feminina. In Edição standard brasileira das obras completas de Sigmund Freud (Vol. 21, pp. 257-276, C. M. Oiticica, Trad.). Rio de Janeiro: Imago. (Trabalho originalmente publicado em 1931)

Gadamer, H-G. (1976). Verité et méthode: les grandes lignes d'une hermeneutique philosophique. Paris: Éditions du Seil.

Gay, P. (1989). Freud, uma vida para o nosso tempo. São Paulo: Companhia das Letras.
Gerber, I. (1999). Caminhos da intersubjetividade: Ferenczi, Bion, Matte-Blanco. Psicologia USP, 10(1), 141-155.

Harmat, P. (1987). Psychoanalysis in Hungary since 1933. International Review of Psycho-Analysis, 14(4), 503-508.

Haynal, A. (1995). A técnica em questão: controvérsias em psicanálise - de Freud e Ferenczi a Michael Balint. São Paulo: Casa do Psicólogo/ Clínica Roberto Azevedo.

Hazan, Y. (1999). From Ferenczi to Kohut: from confusion of tongues to selfobject. American Journal of Psychoanalysis, 59(4), 333-343.

Katz, C. S. (Org.). (1996). Férenczi: história, teoria e técnica. São Paulo: Editora 34

Landa, F. (1999). Ensaio sobre a criação teórica em psicanálise: de Ferenczi a Nicolas Abraham e Maria Torok. São Paulo: UNESP, FAPESP.

Laplance, J., \& Pontalis, J-B. (1992). Vocabulário de psicanálise. São Paulo: Martins Fontes.

Lorin, C. (1983). Le jeune Ferenczi, premiers écrits (1899-1906). Paris: Aubier-Flamarion.

Martin-Cabre, L. J. (2001). Winnicott and Ferenczi: trauma and the maternal analyst. In M. Bertolini, A. Giannakoulas, \& M. Hernandez (Orgs.), Squiggles and spaces revisiting the work of D. W. Winnicott (Vol. 2, pp. 179-184). Londres: Whurr.

Mezan, R. (1985). Freud: pensador da cultura. São Paulo: Brasiliense.

Mezan, R. (1988). Problemas de uma história da psicanálise. In J. Birman (Org.), Percursos na história da psicanálise (pp. 15-41). Rio de Janeiro: Taurus.

Migone, P. (1994). The problem of 'real' trauma and the future of psychoanalysis. International Forum of Psychoanalysis, 3(2), 89-96.

Nachin, C. (2001). From 'tact' in Ferenczi to 'resonance' in Nicholas Abraham. Psychoanalysis and History, 3(2), 171-177.

Pinheiro, M. T. (1993). Trauma e melancolia. Percurso, 6(10), 50-55.

Roudinesco, E. (1988). História da psicanálise na França: a batalha dos cem anos - 1925-1985 (Vol. 2). Rio de Janeiro: Jorge Zahar.

Roudinesco, E. (1989). História da psicanálise na França: a batalha dos cem anos - 1888-1939 (Vol. 1). Rio de Janeiro: Jorge Zahar.

Roudinesco, E. (1995). Genealogias. Rio de Janeiro: Relume-Dumará.

Sabourin, P. (1988). Ferenczi: paladino e grão-vizir secreto. São Paulo: Martins Fontes.

Sanches, G. P. (1993). Sándor Ferenczi e a ampliação dos limites terapêuticos da psicanálise. Percurso, 6(10), 40-44.

Sanches, G. P. (1994). Sándor Ferenczi e as bases para uma nova concepção de relação psicanalítica. Dissertação de mestrado não-publicada, Pontifícia Universidade Católica de São Paulo, São Paulo.

${ }^{1}$ Este artigo é fruto de elaboração conjunta dos autores, mais precisamente das reuniões entre o orientador da tese, Gilberto Safra, e o doutorando, Gabriel Z. Lescovar.

Gabriel Zaia Lescovar, mestre em psicologia clínica pela Pontifícia Universidade Católica de São Paulo, é doutorando no Instituto de Psicologia da Universidade de São Paulo, bolsista FAPESP e membro do Laboratório de Estudos da Transicionalidade. Endereço para correspondência: Rua Ministro Gastão Mesquita, 769, apto. 24; São Paulo, SP; CEP 05012-010. E-mail: gabriellescovar@uol.com.br

Gilberto Safra, livre docente no Instituto de Psicologia da Universidade de São Paulo, é professor no curso de Pós-graduação em Psicologia Clínica da Pontifícia Universidade Católica de São Paulo, e coordenador do Laboratório de Estudos da Transicionalidade. E-mail: iamsafra@uol.com.br 